$$
y_{0}^{2 m}
$$


Distribuclón del ingreso e incidencia de la pobreza a lo largo del ajuste

Oscar Altimir

Nuevas orientaciones para la gestión pública

Eugenio Lahera

Industrias petroquímica y de máquinas herramientas:

estrategias empresariales

Daniel Chudnovsky, Andrés López y Fernando Porta

Productividad, crecimiento y exportaciones industriales de Brasil

Regis Bonelli

Maquila en el Caribe: la experiencia de Jamaica

Larry Willmore

Elasticidad-precio de las exportaciones agrícolas de Centroamérica

De la inflaclón crónica a la inflación moderada en el Ecuador

Luis I. Jácome Hidalgo

Nuevas estrategias de las empresas transnacionales en la Argentina

Bernardo Kosacoff y Gabriel Bezchinsky

Informalidad y pobreza en América Latina

Guillermo Rosenbluth

Crisis y alternativas en los procesos de regionalización

Sergio Boisier

Una perspectiva cultural de las propuestas de la CEPAL

Fernando Calderón, Martín Hopenhayn y Ernesto Ottone

La CEPAL y el neoliberalismo: entrevista a Fernando Fajnzylber

Orientaciones para los colaboradores de la Revista de la CEPAL

Publicaciones reclentes de la CEPAL 


\section{De la inflación crónica a la inflación moderada en el Ecuador}

\section{Luis I. Jácome Hidalgo}

Corporación de Estudios para el Desarrollo

(CORDES), Quito.
Desde septiembre de 1992 está en vigencia en Ecuador un nuevo programa de estabilización. Aquí se examina la naturaleza de esta política económica, en una breve comparación con otras experiencias de estabilización en el país en los años ochenta, y sus logros hasta la fecha. Hasta ahora se ha logrado reducir la tasa de inflación a un 32\% anual al finalizar 1993, luego de cinco años en que fue superior al $55 \%$ en promedio. Por lo tanto, se ha pasado de una situación de inflación crónica a otra de inflación moderada, que ha estado acompañada de una baja en la actividad económica, pese a la caída de las tasas de interés reales, y del uso del tipo de cambio como ancla nominal. A pesar de esto último, la balanza comercial no ha sufrido un gran deterioro, como cabía esperar. El estudio finaliza con un rápido examen de los obstáculos que habrán de vencerse hacia adelante, teniendo en cuenta la perspectiva de una nueva baja apreciable de la inflación en 1994, como la que han planteado las autoridades económicas. 


\section{Introducción}

La evolución de la economía ecuatoriana en los últimos diez años ha sido fundamentalmente inestable debido a causas de origen interno y externo. Las tasas de ahorro e inversión cayeron notablemente en comparación con las de la década anterior, y el crecimiento económico fue moderado. En general, las condiciones de vida de la mayor parte de la población se deterioraron, y la economía ecuatoriana se rezagó respecto del resto de América Latina, luego de que en los años setenta había sido una de las que habían mostrado mayor dinamismo.

Los problemas se agravaron particularmente a partir de 1987, año en que empezó a acelerarse el proceso inflacionario. Pese a los esfuerzos de estabilización desplegados desde la segunda mitad de 1988, las cosas no mejoraron puesto que los precios subieron en promedio un 57\% por año entre ese año y 1992.

En septiembre de 1992 se aplicó un nuevo programa de estabilización, a los pocos días de asumir el poder un nuevo gobierno. Hasta ahora los resultados son alentadores, pues se han restablecido los equilibrios macroeconómicos, la inflación se ha desacelerado significativamente $\mathrm{y}$ se ha elevado sustancialmente el nivel de las reservas internacionales. Al mismo tiempo, se ha producido una marcada apreciación real del tipo de cambio y el crecimiento económico se ha desacelerado, quizás inevitablemente. Aunque se ha avanzado mucho en la lucha contra la inflación, queda aún camino por recorrer, puesto que por ahora se ha pasado de una inflación crónica a una inflación moderada. ${ }^{1}$ Lo sucedido en otros países de la región indica que esta última es particularmente difícil de doblegar.

Este artículo se propone evaluar los resultados del programa de ajuste implantado en septiembre de 1992. Complementariamente, analiza brevemente las perspectivas de la economía en el corto plazo, dentro del objetivo planteado por el gobierno de reducir la inflación a un nivel significativamente más bajo (sección I). Revisa los antecedentes de la implantación del actual programa de estabilización, pues ello contribuye a entender mejor la naturaleza de la estrategia de estabilización elegida (sección II). Examina tal estrategia (sección III), haciendo una breve comparación con anteriores programas de estabilización ensayados en el país en los años ochenta. Analiza la situación actual y señala los logros y debilidades de la política aplicada (sección IV). Hace algunas breves reflexiones sobre la viabilidad de lograr en 1994 la nueva baja apreciable de la inflación planteada por el gobierno (sección V). Y por último, extrae las conclusiones más importantes (sección VI).

\section{II}

\section{Antecedentes del actual programa de estabilización}

Si bien los problemas que ha vivido el Ecuador en la última década suelen asociarse con la crisis de la deuda externa, ellos en realidad germinaron en los años setenta y se manifestaron al comenzar los ochenta. En efecto, cuando la economía empezó a crecer diná-

$\square \mathrm{El}$ autor agradece los comentarios de Augusto de la Torre, Santiago Bayas y José Samaniego, eximiéndolos de toda responsabilidad por los errores que pueda haber en este artículo.

1 Esta inflación suele definirse como aquélla en que la tasa de crecimiento de los precios está entre 15 y $30 \%$ anual. micamente con el inicio de las exportaciones de petróleo y el posterior aumento de su precio en el mercado internacional, se fueron acumulando distorsiones que se manifestaron a través de elevados desequilibrios en los sectores fiscal y externo. ${ }^{2}$ Los proble-

\footnotetext{
2 El mecanismo de transmisión de este shock externo fue la apreciación real del tipo de cambio, que estimuló una asignación de recursos favorable a las actividades de producción y consumo interno, en detrimento del sector de bienes transables en el mercado internacional (con la excepción del petróleo). Este fenómeno ha
} 
mas se agudizaron en los primeros meses de la reinstauración de la democracia en el país —esto es, hacia fines de 1979 — tras la adopción de medidas que significaron una expansión fiscal y un fuerte encarecimiento de los costos de producción. ${ }^{3}$

La situación descrita se pudo mantener mientras existieron bajas tasas de interés internacionales y, en general, mientras se pudo contar con el financiamiento externo requerido. La crisis de la deuda externa, por lo tanto, dejó al descubierto problemas que se habían acumulado a lo largo de años anteriores.

A partir de ese momento, la vulnerabilidad externa de la economía aumentó. Varios hechos exógenos de los años siguientes ocasionaron importantes pérdidas de divisas al país: entre ellos, las inundaciones de finales de 1982 y 1983 motivaron una contracción de las exportaciones tradicionales, y el terremoto de 1987 obligó a suspender las exportaciones de petróleo por alrededor de cinco meses. En general, hubo un persistente deterioro de los términos de intercambio a lo largo de los años ochenta. Para enfrentar estos problemas se adoptaron políticas de ajuste en el frente externo, pero éstas no siempre fueron acompañadas de políticas coherentes por el lado de la demanda agregada, de manera que la década transcurrió en medio de un creciente proceso inflacionario. El cuadro 1 ofrece una visión general de la evolución de la economía ecuatoriana en ese período.

CUADRO 1

Ecuador: Indicadores macroeconómicos, 1980-1990

\begin{tabular}{|c|c|c|c|c|c|c|c|c|c|}
\hline \multirow{3}{*}{ Años } & \multicolumn{4}{|c|}{ Crecimiento anual } & \multicolumn{3}{|c|}{ Como proporción del PIB } & \multicolumn{2}{|c|}{ Indice } \\
\hline & \multirow{2}{*}{$\begin{array}{l}\text { PIB } \\
\text { real }\end{array}$} & \multirow{2}{*}{$\underset{\mathrm{a}}{\mathrm{IPC}}$} & \multirow{2}{*}{$\underset{\mathrm{b}}{\mathrm{M} 1}$} & \multirow{2}{*}{$\begin{array}{c}\text { TI } \\
\mathrm{c}\end{array}$} & \multicolumn{2}{|c|}{ Balance } & \multirow{2}{*}{$\begin{array}{c}\text { Señorea- } \\
\mathrm{je}^{\mathrm{e}}\end{array}$} & \multirow{2}{*}{$\underset{\mathbf{f}}{\mathrm{TCER}}$} & \multirow{2}{*}{$\begin{array}{c}\text { Salario } \\
\text { real }\end{array}$} \\
\hline & & & & & $\underset{d}{\text { SPNF }}$ & Cta.Cle. & & & \\
\hline 1980 & 4.9 & 16.3 & 28.0 & 6.6 & -4.7 & -7.0 & 1.4 & 110.0 & 139.1 \\
\hline 1981 & 3.9 & 17.2 & 11.3 & -5.8 & -5.6 & -10.0 & 0.7 & 125.2 & 121.4 \\
\hline 1982 & 1.2 & 24.4 & 20.2 & -16.1 & -6.7 & -11.5 & 0.9 & 122.6 & 109.3 \\
\hline 1983 & -2.8 & 52.5 & 30.4 & -22.4 & $\ldots$ & -1.2 & 1.0 & 116.7 & 101.4 \\
\hline 1984 & 4.2 & 25.1 & 42.2 & 0.4 & -0.6 & -2.6 & 2.2 & 96.3 & 102.0 \\
\hline 1985 & 4.3 & 24.4 & 23.6 & -2.0 & 1.9 & 1.0 & 1.5 & 100.0 & 100.0 \\
\hline 1986 & 3.1 & 27.3 & 20.4 & -27.1 & -5.1 & -5.7 & 2.0 & 80.5 & 103.6 \\
\hline 1987 & -6.0 & 32.5 & 32.3 & -5.2 & -9.6 & -11.9 & 2.3 & 61.9 & 95.5 \\
\hline 1988 & 10.5 & 85.7 & 53.8 & -22.0 & -5.1 & -5.8 & 3.1 & 46.5 & 78.1 \\
\hline 1989 & 0.3 & 54.2 & 38.1 & 2.7 & -2.9 & -4.6 & 1.8 & 53.8 & 61.6 \\
\hline 1990 & 2.3 & 49.5 & 52.2 & 5.7 & 1.1 & -1.2 & 2.4 & 49.5 & 57.9 \\
\hline
\end{tabular}

Fuente: FMI, Estadísticas financieras internacionales, varios números. Banco Central del Ecuador, Información estadística mensual, varios números.

${ }^{a}$ Indice de precios al consumidor. ${ }^{b}$ Oferta monetaria. ${ }^{c}$ Términos de intercambio. ${ }^{d}$ Sector público no financiero. ${ }^{\mathrm{e}}$ Incremento anual de la base monetaria ${ }^{\mathrm{f}}$ Tasa de cambio efectiva real (su disminución indica depreciación).

A comienzos de 1983 se implantó un primer programa de estabilización. Con él se buscaba enfrentar la crisis de la deuda externa y los efectos destructivos de las inundaciones en la costa ecuatoriana, que redujeron las exportaciones de banano, café y cacao. Este programa de ajuste tuvo características puramente ortodoxas: se basó en un ajuste fiscal y monetario complementado con una política

sido ampliamente estudiado en la literatura económica bajo el nombre de "enfermedad holandesa". Al respecto, véase por ejemplo Corden y Neary (1982) y Corden (1984), y con relación específica al Ecuador, De la Torre (1987) y Jácome (1989).

3 Ejemplos en este sentido constituyen la duplicación de los salarios mínimos y la reducción de la jornada de trabajo en casi $10 \%$. de depreciación real del tipo de cambio. Como resultado, entre 1982 y 1983 se eliminó el déficit del sector público no financiero, que llegaba a casi $7 \%$ del PIB, y el desequilibrio de la cuenta corriente externa disminuyó de más del $11 \%$ al $1 \%$ del PIB. Esto permitió que se desacelerara la inflación de fin de período a menos de la mitad desde 1983 a 1984 (de 52.5 al $25.1 \%$ ). El restablecimiento de los equilibrios macroeconómicos y la menor inflación permitieron que en 1984 y 1985 la economía se reactivara y creciera a tasas superiores al $4 \%$.

Este proceso de recuperación fue interrumpido por la rápida caída del precio del petróleo en 1986 y por el terremoto de 1987. Para compensar la merma 
de divisas, el país dejó de servir su deuda externa comercial. En el frente interno, en cambio, las políticas no fueron coherentes, pues lejos de contraerse se fueron tornando crecientemente expansivas. Como consecuencia, los desequilibrios fiscal y externo se agudizaron y el incremento anual de la base monetaria ("señoreaje") se acentuó, provocando una caída de las reservas internacionales netas a valores negativos hacia mediados de 1988, una inflación acumulada en los primeros siete meses de ese año de cerca de $50 \%$ anual, y grandes distorsiones en los precios relativos. Este deterioro económico coincidió con el último año del gobierno en funciones en aquella época.

A los pocos días de acceder al poder, a finales de agosto de 1988, el nuevo gobierno adoptó un programa de estabilización que denominó Plan de Emergencia Nacional, con características similares a las del programa económico ensayado exitosamente en 1983. En esencia, se buscaba realinear los precios relativos y reducir gradualmente los desequilibrios macroeconómicos existentes. Luego del ajuste inicial, ${ }^{4}$ este programa tuvo como componentes importantes el establecimiento de una política cambiaria basada en ajustes graduales y preanunciados, que pretendía mantener la competitividad del sector transable de la economía, y por otro lado, ajustes también graduales en los precios de los bienes y los servicios públicos, particularmente de la gasolina. No obstante estos esfuerzos, al final de 1989 la inflación había bajado sólo al 54\%, tasa superior a la meta de $30 \%$ anunciada por el gobierno, lo que minó la credibilidad del programa económico. Al mismo tiempo el costo en materia de producción fue alto, pues el crecimiento resultó apenas positivo.

A partir de ese momento, el esfuerzo fiscal fue menor, en parte debido a que el Ecuador se benefició del alza de los precios del petróleo ocasionada por la guerra del Golfo Pérsico. Al mismo tiempo, la política cambiaria se mantuvo inalterable, incluyendo ocasionales ajustes discretos para mantener estable el tipo de cambio real bajo criterios sustentados en la teoría de la paridad del poder de compra. ${ }^{5}$ En el marco de

4 Las medidas incluyeron una devaluación de $45 \%$, la elevación de tarifas públicas (en particular, se duplicó el precio interno de la gasolina), la eliminación del subsidio al trigo, un aumento salarial del orden del $16 \%$, y otras medidas de carácter impositivo. esta política económica y de un entorno internacional favorable, la inflación se mantuvo alrededor del 50\% en 1990 y 1991 , y el crecimiento se aceleró al 3.0 y $4.9 \%$, respectivamente. Este fenómeno respondió en gran medida a la expansión de las exportaciones (de banano y camarón), que a su vez mejoró el nivel de las reservas internacionales.

En el ámbito estructural, se llevaron a cabo importantes transformaciones. Las más destacables fueron la apertura de la economía, con la cual se redujo el nivel promedio de los aranceles aduaneros más los recargos a las importaciones del 37 al $15 \%$, aproximadamente, al tiempo que se disminuyó la dispersión arancelaria. Esta apertura de la economía fue complementada con el establecimiento gradual de una zona de libre comercio con Colombia y Venezuela. Pero, por otro lado, el país continuó acumulando atrasos en el servicio de su deuda externa comercial, situación que le creó una imagen negativa ante la comunidad financiera internacional.

Durante la primera mitad de 1992 la economía se deterioró más, en coincidencia con el período de transición a un nuevo gobierno. El exceso de demanda interna originado en la expansión fiscal impactó, más que en el nivel de precios, en las reservas internacionales netas, cuyo saldo se redujo a menos de la mitad en los primeros siete meses del año. Además, el tipo de cambio real y las tarifas de los bienes y servicios públicos se rezagaron con respecto al valor real que habían mantenido durante los tres años precedentes.

Lo que ocurrió en esos meses fue una típica situación de "crisis de balanza de pagos" (Krugman, 1979): los agentes económicos desarrollaron expectativas de una futura devaluación, que sería adoptada por el nuevo gobierno en el marco de una nueva estrategia de estabilización; en consecuencia, se produjo un ataque al tipo de cambio, es decir, una fuga de capitales que ocasionó la disminución de las reservas internacionales del Banco Central, una rápida subida de las tasas de interés internas y, en general, una desmonetización de la economía.

5 Adicionalmente, se otorgó un subsidio al sector exportador al disponer que el Banco Central comprara divisas en forma anticipada a este sector, incluyendo una reliquidación por la diferencia producida entre la cotización vigente a la fecha de entrega de las divisas y la del embarque de la mercancía. Las pérdidas cambiarias por este concepto alcanzaron a cerca del $1 \%$ del PIB en 1991, lo que constituyó una fuente importante de inyección primaria de liquidez. 


\section{III}

\section{El Plan Macroeconómico de Estabilización}

El gobierno que asumió sus funciones en agosto de 1992 implantó a los pocos días un nuevo programa de ajuste: el Plan Macroeconómico de Estabilización (PME). Este planteó como objetivo fundamental de corto plazo lograr una "rápida reducción de la inflación y el fortalecimiento de la posición fiscal y externa"; y dentro de un horizonte de largo plazo, definió como pilar fundamental la "reforma del sector público", para dar "viabilidad a la modernización y al desarrollo económico" del país (Banco Central del Ecuador, 1992).

Este programa era de naturaleza distinta a la de los dos anteriores. En esta ocasión se diseñó una estrategia de choque dirigida a desacelerar rápidamente la inflación, en reemplazo del enfoque más gradual que había prevalecido antes. Además, se utilizó como ancla el tipo de cambio, a diferencia de los dos programas anteriores, en los que fue el dinero la variable que cumplió esta función. Por lo tanto, el tipo de cambio pasó a ser un instrumento de estabilización, a costa de la competitividad de los sectores de la economía que comercian con el exterior. En este sentido, el nuevo experimento es similar a los programas de ajuste ensayados en el Cono Sur hacia finales de los años setenta y que han sido objeto de numerosos estudios (Solimano, 1990; Kiguel y Liviatan, 1992; Végh, 1992).

Nuevamente, tanto el tipo de cambio como los precios de los bienes y servicios públicos subieron significativamente al inicio del programa. Sin embargo, en esta ocasión el ajuste fue mayor, a fin de dejar espacio para mantener estables estas variables en el futuro. De esta manera se rompió en buena medida la inercia inflacionaria alimentada por los permanentes ajustes que se venían realizando en estos precios. Las principales medidas adoptadas inicialmente incluyeron una devaluación de alrededor de $30 \%$, e incrementos importantes en los precios de los derivados del petróleo y la electricidad. En particular, se aumentó el precio de las gasolinas en más de $125 \%$, y el gas de uso doméstico en cerca de $300 \%$. Posteriormente, los dos puntales de la nueva política económica han continuado siendo la política cambiaria y el ajuste fiscal.

En particular, el manejo cambiario ha estado orientado a romper las expectativas inflacionarias que tenían hasta hace poco los agentes económicos, las mismas que en gran parte estaban asociadas al régimen cambiario anterior, basado en minidevaluaciones preanunciadas. Esta vinculación estrecha entre las variaciones en el tipo de cambio nominal y en el nivel de precios se puede apreciar en el gráfico 1 . Con este propósito, luego de la devaluación inicial se definió el tipo de cambio como "ancla" nominal, aunque sin establecer un tipo de cambio fijo.

GRAFICO 1

Ecuador: Devaluación e inflación (Evolución trimestral)

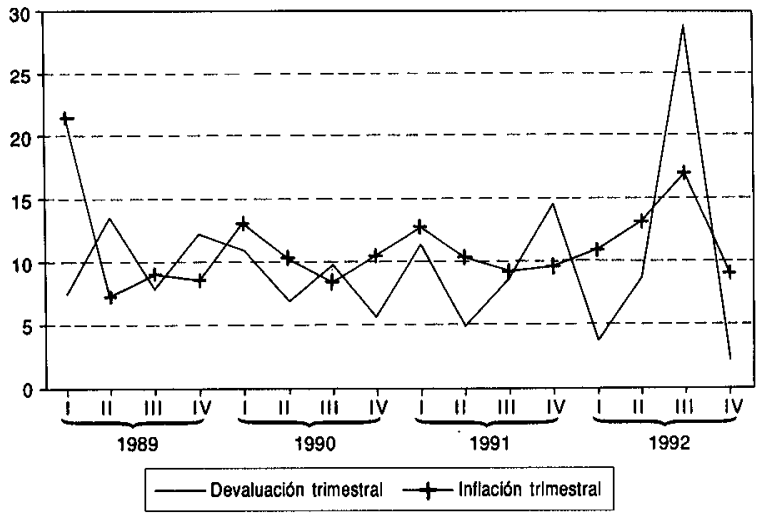

Desde el punto de vista operativo, se estableció una banda dentro de la cual se permitía que el tipo de cambio flotara, con el objeto de mantenerlo estable conforme a las directrices del Banco Central. Esta modalidad evitó tanto los problemas macroeconómicos originados por la vigencia de reglas de ajuste del tipo de cambio nominal que buscan mantener un determinado nivel del tipo de cambio real (Adams y Gros, 1986; Montiel y Ostry, 1991), como la restricción de mantener un tipo de cambio fijo por un tiempo prolongado, que tiende a generar una apreciación real del tipo de cambio y otras consecuencias macroeconómicas. Posteriormente, la banda fue eliminada, de manera que hoy se tiene un régimen de flotación dirigida.

Puesto que el techo de la banda se volvió creíble como consecuencia de la sobredevaluación inicial, y que en el transcurso de los meses se mostró una severa disciplina fiscal, las expectativas de depreciación 
se redujeron apreciablemente. De esta manera, la rentabilidad de los activos financieros en sucres se volvió muy atractiva, lo que estimuló la entrada de capitales.

Por lo tanto, la disciplina en el manejo de las finanzas públicas fue identificada como una condición necesaria para el éxito del programa de estabilización, como lo había demostrado la experiencia exitosa en otros países de la región que lograron estabilizar sus economías. La política aplicada ha descansado fundamentalmente en una severa restricción del gasto estatal, sin recurrir a la generación de ingresos por el lado de los impuestos.

La política monetaria ha tenido un rol menos protagónico. Esto no es motivo de sorpresa, puesto que al mantenerse estable el tipo de cambio, la política monetaria tiende a ser endógena. En este contexto, durante los primeros meses los esfuerzos monetarios apuntaron a esterilizar parcialmente la monetización originada en el crecimiento de las reservas internacionales, con el fin de evitar un excesivo aumento de la cantidad de dinero en la economía. Recientemente, el énfasis se ha desplazado al objetivo de moderar las variaciones de las tasas de interés.

A diferencia de lo que ha ocurrido con programas de estabilización adoptados en otros países como México e Israel (los denominados heterodoxos), al comienzo el PME no incorporó explícitamente la política de ingresos como parte integral de la estrategia antiinflacionaria. Esto es explicable, dado el bajo nivel de indización que caracteriza a la economía ecuatoriana y, sobre todo, por la carencia de un ambiente favorable al consenso entre los diferentes sectores de la sociedad.

Por último, en el campo social es poco lo que se ha hecho. No ha existido por parte del gobierno la intención de darle un contenido social al gasto público, como hicieron otros países (como Chile y México) que buscaron compensar el costo del ajuste. En este sentido, la posición gubernamental ha sido la de que el mayor beneficio social para la población es la reducción de la inflación.

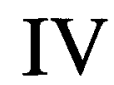

\section{Resultados del Plan Macroeconómico de Estabilización}

Si se hace un balance, la aplicación del PME ha dado resultados positivos, pues la mayoría de los principales indicadores macroeconómicos muestran una evolución favorable (cuadro 2). En particular, la inflación se ha desacelerado notablemente, se ha alcanzado una sólida posición financiera externa y se ha reducido significativamente el déficit fiscal, pese a que el entorno internacional no ha sido muy favorable al desenvolvimiento de la economía interna. Por otro lado, la actividad económica parece haber sufrido una marcada desaceleración y el tipo de cambio real muestra un creciente rezago. En el ámbito estructural los avances son menores que los logros en materia de estabilización.

\section{Baja de la inflación y aumento de las reser- vas internacionales}

El logro más importante del PME es sin lugar a duda la baja de la inflación a un nivel cercano al $30 \%$ al finalizar 1993, lo que implica que el crecimiento de los precios se redujo casi a la mitad desde diciembre de 1992. Este resultado ha tenido dos efectos importantes. Primero, rompió la inercia inflacionaria que venía arrastrando la economía ecuatoriana durante los cinco años precedentes, contribuyendo así a que los agentes económicos elaboren expectativas de una menor inflación futura. En este sentido es ilustrativo el gráfico 2, que muestra la evolución mensual de la inflación media en 1988-1992 y en 1993.6 Se comprueba así que, en este último año - -salvo en el mes de mayo, en que el gobierno enfrentó una severa crisis política interna que puso en duda la permanencia del ajuste económico y provocó un brote especulativo-, la tasa de inflación mensual fue claramente inferior al promedio mensual del período 1988 a 1992.

Un segundo efecto es el de mantener la credibilidad del programa, pues la inflación al cerrar 1993 estaba muy cerca de la meta anunciada originalmente por el gobierno.

6 Se supuso que en el mes de diciembre de 1993 habría una inflación del $1.5 \%$. 
CUADRO 2

Ecuador: Principales indicadores macroeconómicos

\begin{tabular}{lrrr}
\hline & 1991 & 1992 & $1993^{a}$ \\
\hline & \multicolumn{3}{c}{ Cambios porcentuales } \\
& 4.9 & 3.5 & 1.5 \\
Crecimiento del PIB & 49.0 & 60.2 & 32.0 \\
Inflación (fín del año) & 48.7 & 54.6 & 46.5 \\
Inflación (promedio anual) & 4.8 & -1.8 & 15.0 \\
Tipo de cambio efectivo real & & & \\
(el signo - indica depreciación) & & 43.3 & 42.0 \\
Oferta monetaria & 47.1 & 61.7 & 63.0 \\
Cuasidinero & 63.6 & -3.2 & -6.0 \\
Términos de intercambio & -5.3 & &
\end{tabular}

En valores absolutos (millones de dólares)

Reservas internacionales

Exportaciones fob

Importaciones fob

\begin{tabular}{rrr}
760 & 782 & 1250 \\
2851 & 3008 & 2812 \\
2207 & 2027 & 1940 \\
\multicolumn{3}{c}{ Como porcentaje del PIB }
\end{tabular}

Sector público no financiero

Balanza comercial

$-2.0$

$-2.9$

$-0.5$

Cuenta corriente

Inversión bruta
Deuda externa total ${ }^{b}$

afianza su posición financiera externa, sino que hace más viable una potencial reestructuración de la deuda externa comercial ecuatoriana en los próximos meses. Por cierto, este crecimiento de las reservas se ha debido fundamentalmente a los ingresos de capital de corto plazo y no a un mejoramiento comercial, según veremos más adelante.

GRAFICO 3

Ecuador: Reservas internacionales netas, junio de 1992 a diciembre de 1993 (Millones de dólaress)

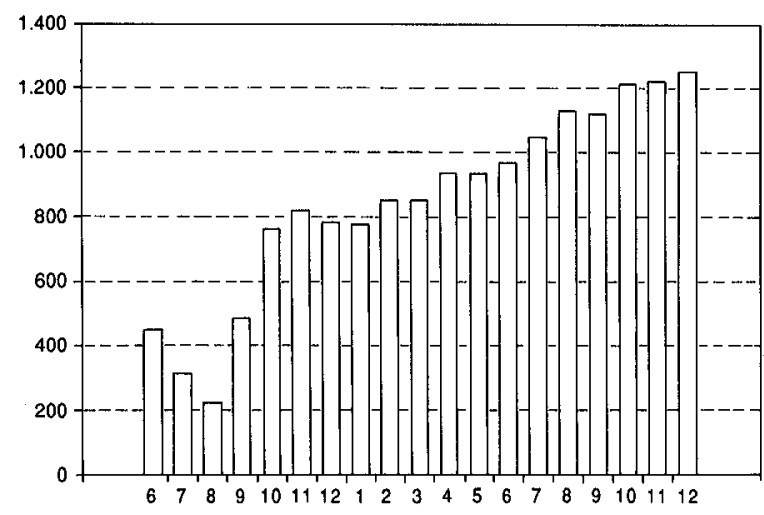

Fuente: FMI Estadísticas financieras internacionales, varios números. Banco Central del Ecuador, Información estadística mensual, varios números.

a Cifras proyectadas.

${ }^{b}$ Excluye intereses sobre atrasos en el pago de intereses para el caso de la deuda externa sujeta a reestructuración dentro del Plan Brady.

GRAFICO 2

Ecuador: Inflación mensual, 1988-92 y 1993

(Porcentajes)

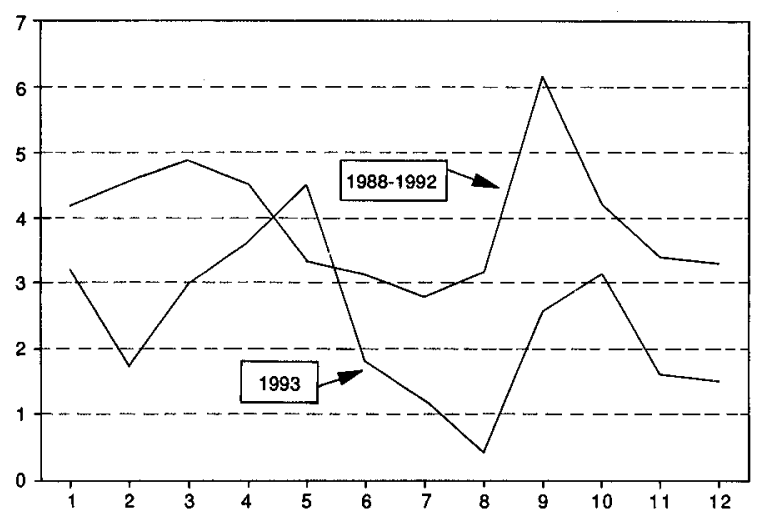

Un tercer resultado positivo es la recuperación de la reserva monetaria internacional y su incremento hasta niveles nunca antes registrados, esto es, alrededor de 1250 millones de dólares a fines de 1993 (gráfico 3). Dicho nivel de reservas internacionales no sólo contribuye a la estabilización del país, pues

\section{Ajuste fiscal, apreciación real y caída de ta- sas de interés}

Tal como era de preverse, a estos resultados efectivamente contribuyeron tanto la fuerte restricción del gasto público como la modalidad de política cambiaria aplicada. Como consecuencia, ingresaron capitales desde el exterior y las tasas de interés cayeron.

Una medida del ajuste fiscal fue la acumulación de depósitos del sector público no financiero en el Banco Central durante el primer año de implantación del PME, la que representó alrededor del 3\% del PIB de 1993. Esta política hizo que en ese año se llegara casi a un equilibrio de las cuentas fiscales. Tan importante acumulación de depósitos en el Banco Central sirvió, además, para compensar en parte la elevada monetización originada en el crecimiento de las reservas internacionales, y evitar así un crecimiento exageradamente alto de las variables monetarias que, de otra manera, pudo haber perjudicado la lucha contra la inflación.

Esta afirmación tiene respaldo en el gráfico 4, que muestra la estrecha relación entre la evolución de los flujos mensuales de reservas internacionales netas y la de los depósitos netos (créditos menos depósitos) del sector público no financiero en el Banco Central. 
El efecto esterilizador de la restricción fiscal ha reducido en parte las necesidades de colocación de valores de corto plazo (Bonos de estabilización monetaria) por parte del Banco Central y con ello se ha evitado un incremento desmesurado del déficit cuasifiscal.

GRAFICO 4

Ecuador: Variación de las reservas monetarias internacionales y de los créditos netos al sector público no financiero, septiembre de 1992 a noviembre de 1993

(Flujo mensual)

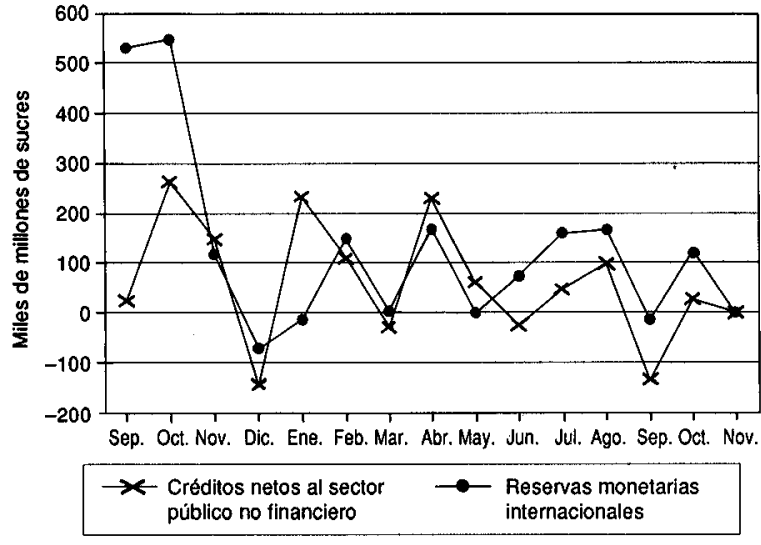

Pero ni siquiera un esfuerzo fiscal tan grande hubiera sido suficiente para bajar la inflación a los niveles alcanzados. La estrategia de sobredevaluar el sucre inicialmente abrió espacio para una posterior estabilidad de la tasa de cambio nominal en 1993. De esta manera, además de modificarse las expectativas inflacionarias, efectivamente se aminoró la inercia que venía de años anteriores.

Adicionalmente, el impacto de la reforma arancelaria y del establecimiento de la zona de libre comercio contribuyó a desacelerar la inflación. Esta apertura de la economía, asociada al rezago cambiario ya señalado, determinó que los precios de los bienes transables se mantuvieran estables.

Por otro lado, la sobredevaluación inicial y la posterior estabilidad estimularon una gran entrada de capitales, como se había previsto, con lo cual se generó una presión a la baja del tipo de cambio nominal y una creciente apreciación real. $\mathrm{El}$ ingreso masivo de capitales al Ecuador respondió a los mismos factores que explican este fenómeno en otros países de la región (Calvo, Leiderman y Reinhart, 1993), y en general fue un shock externo que contribuyó de manera importante al proceso de estabilización de la economía ecuatoriana. Por sobre todo, estos capitales ingresaron al país porque la rentabilidad de los activos en sucres fue largamente superior durante los primeros meses de vigencia del programa económico, situación que se mantuvo durante casi todo 1993 (gráfico 5). ${ }^{7}$ Ese flujo de capitales contribuyó significativamente al rápido mejoramiento anotado de las reservas internacionales desde septiembre de 1992 en adelante.

GRAFICO 5

Ecuador: Diferencia de rentabilidad entre los activos en sucres y los activos en dólares, 1993

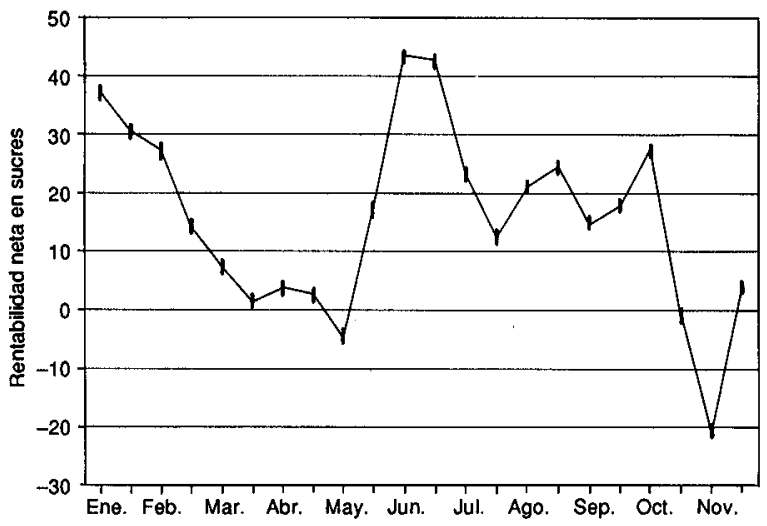

De esta manera se produjo una rápida remonetización de la economía a partir de septiembre de 1992 (gráfico 6), en niveles compatibles con la desaceleración del crecimiento de los precios. Esto se explica porque la demanda de dinero aumentó en el marco

GRAFICO 6

Ecuador: Base monetaria, 1992-1993

(Tasa de crecimicento anual)

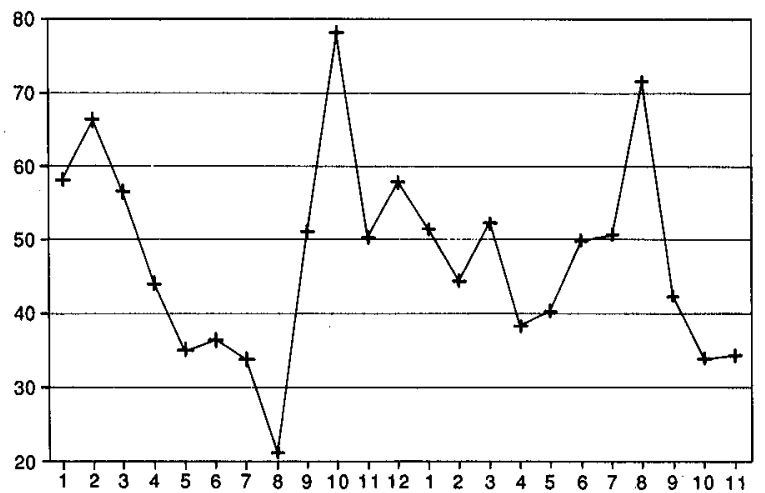

7 En el gráfico 5 se compara la rentabilidad de los valores de corto plazo (Bonos de estabilización monetaria) subastados por el Banco Central con vencimiento a 91 días, y la rentabilidad otorgada por la suma de la tasa Prime más la depreciación esperada, esto es, $r-\left(r^{*}+e^{e}\right)$ 
del PME, debido al cambio que se produjo en la cartera de activos de las personas en favor de aquéllos en sucres, por su mayor rentabilidad relativa. Al no producirse un desequilibrio en el mercado monetario, el crecimiento de la cantidad de dinero en la economía no provocó un aumento en el nivel general de precios.

La entrada de capitales desde el exterior y la actitud del Banco Central de esterilizar sólo parte de ellos provocaron una caída de las tasas de interés hasta niveles negativos en valores reales con respecto a la inflación presente (cuadro 3)

CUADRO 3

Ecuador: Tasas de interés reales, 1992 -1993 (Tasas pasivas referenciales a 90 días)

\begin{tabular}{lccc}
\hline & $\begin{array}{c}\text { Tasas nominales } \\
(\%)\end{array}$ & $\begin{array}{c}\text { Inflación } \\
(\%)\end{array}$ & $\begin{array}{c}\text { Tasas reales } \\
(\%)\end{array}$ \\
\hline 1992 & & & \\
Enero & 49.43 & 48.9 & 0.5 \\
Febrero & 49.46 & 48.3 & 1.2 \\
Marzo & 49.80 & 46.7 & 3.1 \\
Abril & 48.58 & 49.6 & -1.0 \\
Mayo & 48.54 & 48.8 & -0.3 \\
Junio & 51.34 & 50.4 & 0.9 \\
Julio & 54.34 & 51.7 & 2.6 \\
Agosto & 61.18 & 52.2 & 9.0 \\
Septiembre & 65.02 & 61.0 & 4.0 \\
Octubre & 48.74 & 65.8 & -17.1 \\
Noviembre & 38.89 & 63.9 & -25.0 \\
Diciembre & 42.30 & 60.2 & -17.9 \\
& & & \\
1993 & & & \\
Enero & 36.89 & 58.5 & -21.6 \\
Febrero & 23.87 & 55.8 & -31.9 \\
Marzo & 21.13 & 56.1 & -35.0 \\
Abril & 26.33 & 53.6 & -27.3 \\
Mayo & 39.94 & 54.8 & -14.9 \\
Junio & 40.68 & 52.1 & -11.4 \\
Julio & 40.68 & 49.9 & -9.2 \\
Agosto & 39.74 & 46.1 & -6.4 \\
Septiembre & 30.69 & 35.5 & -4.8 \\
Octubre & 27.10 & 31.5 & -4.4 \\
Noviembre & 23.12 & 32.3 & -9.2 \\
Diciembre & 27.00 & 33.0 & -6.0 \\
\hline & & & \\
\hline
\end{tabular}

Fuente: Banco Central del Ecuador, Información estadística mensual, varios números.

${ }^{a}$ Cifras proyectadas.

\section{Efecto en el sector real}

No obstante esta baja en las tasas de interés, la actividad económica se desaceleró a raíz de la implantación del programa de ajuste, contrariamente a lo que se ha observado en otros países que implantaron programas de estabilización basados en un "ancla" cambiaria (Kiguel y Liviatan, 1992). En el caso ecuato- riano, el rezago cambiario que se ha ido acumulando, y el impacto de la apertura de la economía implantada en años anteriores, aparentemente tuvieron mucho que ver con el estancamiento económico.

En efecto, si bien la estabilidad del tipo de cambio nominal fue un factor decisivo para bajar la inflación, también provocó efectos negativos, pues hizo que el tipo de cambio real se rezagara durante 1993 en alrededor de $15 \%$ (gráfico 7). ${ }^{8}$ Esta apreciación real del tipo de cambio significó un efecto adverso para aquellos sectores de la economía que comercian con el exterior, y un estímulo para las actividades no transables. El impacto sobre la actividad económica se agudizó en el marco de la apertura de la economía ecuatoriana, puesto que los bienes importados tuvieron un abaratamiento relativo, como consecuencia de la rebaja de los aranceles.

GRAFICO 7

Ecuador: Tipo de cambio real, junio de 1992 a diciembre de 1993

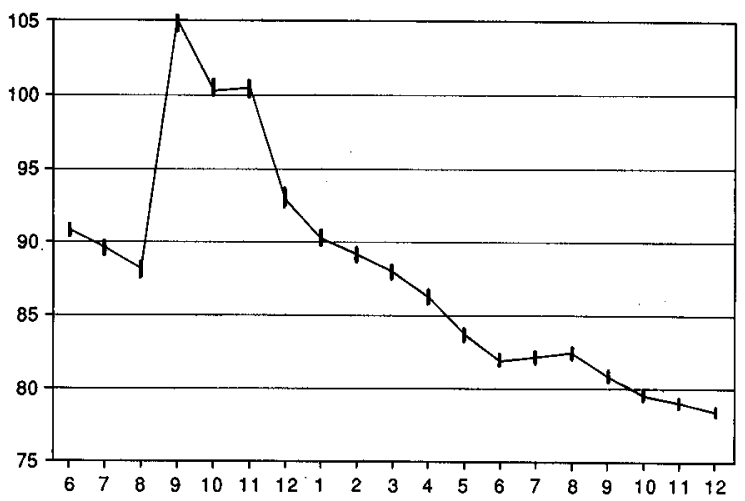

La pérdida de competitividad del sector de bienes transables acentuó la tendencia recesiva de la economía (cuadro 4). El crecimiento del PIB se desaceleró a partir de la adopción del PME hasta llegar a una tasa anual de $1.4 \%$ en el primer semestre de 1993. A su vez, las actividades transables reflejaron una mayor desaceleración, mientras que el sector de la construcción (típicamente no transable) tendió a recuperarse. Este resultado es coherente con la apreciación real del tipo de cambio antes citada.

8 Por cierto, esta cifra no implica una apreciación real equivalente del tipo de cambio, ya que no se está comparando lo ocurrido con respecto a un nivel de equilibrio dado. Además, porque tampoco se consideran los desplazamientos que habría sufrido ese nivel de equilibrio como consecuencia de shocks reales exógenos, tales como variaciones en los términos de intercambio o en los flujos de capital permanentes con el exterior. 
CUADRO 4

Ecuador: Tasas de crecimiento anuales del producto interno bruto real y de algunos sectores, 1991-1993

(Por semestres)

\begin{tabular}{|c|c|c|c|c|c|}
\hline & \multicolumn{2}{|c|}{1991} & \multicolumn{2}{|c|}{1992} & \multirow{2}{*}{$\frac{1993}{\mathrm{I}}$} \\
\hline & I & II & I & II & \\
\hline PIB real & 5.1 & 4.7 & 4.1 & 2.9 & 1.4 \\
\hline (excluido el petróleo) & 4.7 & 4.1 & 4.0 & 2.6 & 0.9 \\
\hline Petróleo & 8.4 & 8.9 & 5.3 & 4.4 & 5.0 \\
\hline Agricultura & 5.6 & 6.4 & 6.5 & 3.0 & 0.8 \\
\hline Industria & 2.4 & 2.7 & 5.7 & 3.2 & 0.7 \\
\hline Construcción & -1.6 & 0.6 & 1.0 & 0.3 & 1.5 \\
\hline
\end{tabular}

Fuente: Banco Central del Ecuador, Cuentas trimestrales $\mathrm{N}^{\circ} 8,1993$.

La caída de la actividad económica estaría revelando además que los agentes económicos han elegido la opción de esperar para realizar sus inversiones, hasta que consideren que se ha consolidado el proceso de estabilización y, en general, que existe el marco propicio para que se produzca una reactivación sostenida.

En cuanto a los salarios, los ingresos mínimos reales a lo largo de 1993 cayeron levemente (gráfico 8). En él se observa la evolución del salario mínimo vital, así como de otras compensaciones y bonificaciones que la ley establece para los niveles mínimos de remuneración.

GRAFICO 8

Ecuador: Evolución de los ingresos mínimos reales, junio de 1992 a diciembre de 1993

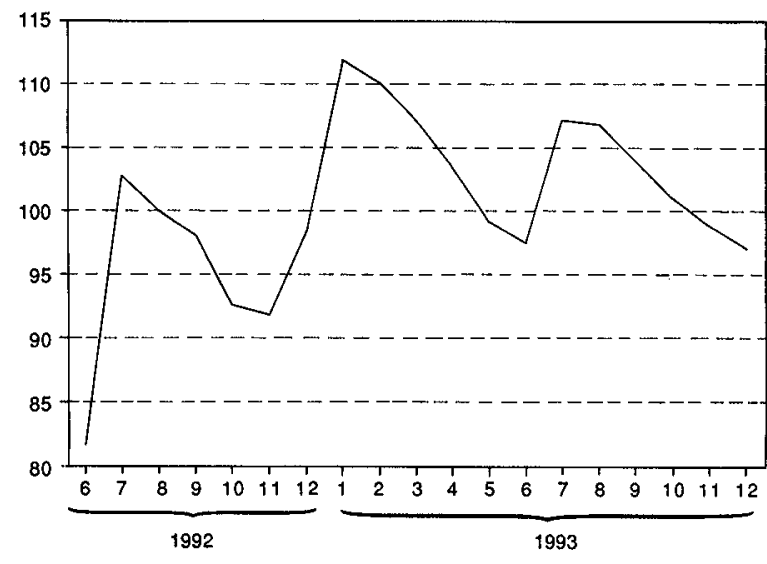

La evolución de los salarios medios no se puede establecer en forma concluyente, dada la falta de información al respecto. Sin embargo, lo más probable es que su situación se haya deteriorado más, puesto que los aumentos decretados por el gobierno fueron nominalmente los mismos para los distintos niveles de remuneración. Por lo tanto, el incremento porcentual fue menor para quienes ganaban por encima del salario mínimo, que eran la mayoría de los asalariados, en circunstancias en que la economía se encontraba virtualmente estancada. Esta flexibilidad de los salarios permitió una más rápida desaceleración de la inflación, a diferencia de lo ocurrido en otros países en que la indización salarial se ha convertido en un freno.

\section{Impacto en el sector externo}

A pesar de la apreciación real del tipo de cambio y de la apertura de la economía, es particularmente notable el hecho de que la balanza comercial tuviera en 1993 sólo un pequeño deterioro con respecto al año anterior y cerrara el año con un superávit aproximado al $6.5 \%$ del PIB. Este resultado atípico contrasta con la experiencia de otros países, como México y Argentina, en donde se ensayaron también programas de estabilización que usaban el tipo de cambio como "ancla", con resultados adversos para la balanza comercial. En el Ecuador, el comportamiento anotado reflejó fundamentalmente una drástica caída del valor de las importaciones, que fue coherente con la disminución de la actividad económica, y que atenuó el impacto de la caída en el valor de las exportaciones.

En efecto, las importaciones en su conjunto disminuirían en 1993 en alrededor de 4\%, debido a la baja en los rubros más importantes en monto, que son las compras de bienes de capital y materias primas. Las importaciones de bienes de consumo, en cambio, aumentarían como era de esperar en cerca de $30 \%$.

El comportamiento de las exportaciones también fue heterogéneo. Por un lado, las exportaciones tradicionales (de petróleo, banano, café, cacao y, en menor medida, de camarón) tuvieron un pobre desempe- 
ño como consecuencia de problemas exógenos y de una baja productividad que les impidió compensar los efectos del rezago cambiario acumulado a lo largo del año. Por otro lado, las exportaciones menores mostraron un dinámico crecimiento que se aproximaría al 50\% entre 1992 y 1993 . Este crecimiento demuestra la elevada capacidad competitiva de estas actividades. Sin embargo, tales exportaciones representan todavía alrededor de $15 \%$ del total de la oferta exportable.

Tomando en cuenta la balanza de servicios, que ha sido crónicamente defícitaria como consecuencia del elevado endeudamiento del país, la cuenta corriente terminaría 1993 con un pequeño déficit. Por consiguiente, sería la cuenta de capital la que estaría explicando el significativo incremento de las reservas internacionales de más de 400 millones de dólares en el año.

Los avances estructurales no han ido a la par de los logros en materia de estabilización. Se han aprobado la Ley de Presupuestos del Sector Público y la Ley del Mercado de Valores. La primera tiene como objetivo fundamental ampliar el control del gasto público por parte del Ministerio de Finanzas, al incluir instituciones que se encontraban fuera de él, como las empresas públicas y otras entidades adscritas al gobierno, con lo que se espera lograr una mayor racionalización del gasto estatal. La segunda busca desarrollar el mercado de capitales en el Ecuador. Parte importante de esta ley es la creación de una unidad monetaria de valor constante con el fin de estimular el ahorro en el país.

La promulgación de la Ley de Modernización del Estado (ley de privatizaciones) se ha dilatado en exceso, pues ha durado casi un año su discusión. Esto último ha afectado adversamente el ambiente de inversión en el país, por ser ésta la principal transformación que el gobierno ofreció realizar. Se podría decir que el escaso éxito en el ámbito estructural tiende a retrasar una eventual reactivación de la actividad económica, no obstante la baja de las tasas de interés internas, pues afecta las expectativas de mantener saneadas las finanzas públicas y, por tanto, de que la estabilización de la economía sea duradera.

Por otro lado, el país continúa sin regularizar sus relaciones con la comunidad financiera internacional. El pago de intereses de la deuda externa comercial se encuentra suspendido desde mediados de 1992; habían venido pagando un 30\% desde mediados de 1989, tras haber estado suspendido totalmente desde comienzos de 1987. Así también, el país se encuentra en atraso con el Club de París desde hace varios meses. No obstante que el gobierno ecuatoriano ha estado negociando durante el último año la reestructuración de su deuda comercial, el que ésta no se haya concretado es un ingrediente adicional de incertidumbre sobre la evolución futura de la economía.

\section{$\mathrm{V}$}

\section{Reflexiones sobre el futuro de corto plazo}

Del análisis anterior se desprende que el Ecuador ha pasado de una inflación crónica (de más del $50 \%$ en promedio durante cinco años) a una inflación moderada (alrededor del 30\% anual). Hacia adelante, la política económica de corto plazo apuntará a cumplir con las metas anunciadas por el gobierno de reducir la inflación al $15 \%$ al final de 1994 , y de reactivar el crecimiento real de la economía a una tasa en torno al $3 \%$ anual.

Los dos objetivos parecen difíciles de conseguir simultáneamente, puesto que implican crecer casi al doble de la tasa que se alcanzaría en 1993, y al mismo tiempo reducir a más de la mitad el alza de los precios con respecto a ese año. El primer objetivo podría ser más alcanzable, tomando en cuenta que está previsto un aumento del $10 \%$ de la producción de petróleo para 1994. Pero parece poco viable la consecución del segundo, dadas las características que en la actualidad presenta la economía ecuatoriana, y tomando en cuenta cuán ardua y prolongada ha resultado en otros países de la región (Colombia, México, Chile) la tarea de bajar niveles de inflación moderada. ${ }^{9}$

En principio, para lograr una rápida reducción de la inflación como la que el gobierno se ha pro-

\footnotetext{
9 Los estudios sobre transiciones desde inflaciones moderadas a inflaciones de un solo dígito abundan cada vez más. Al respecto, véanse Fernández (1992), Mancera (1992), Jadresic (1992), y Dornbusch y Fisher (1993).
} 
puesto, la política económica en 1994 deberá sustentarse al menos en tres elementos importantes. Primero, en el control de la demanda agregada; segundo, en el mantenimiento del tipo de cambio como "ancla" nominal, y tercero, en una política de ingresos coherente con la meta de inflación propuesta. Además, dada la vulnerabilidad de la economía ecuatoriana a choques externos, el comportamiento del entorno internacional desempeñará un papel determinante en los resultados que se alcancen en 1994, en especial en lo que respecta al precio del petróleo en el mercado mundial, al valor de las tasas de interés internacionales y a la posibilidad de un acuerdo de reestructuración de la deuda externa comercial.

En todo caso, no es claro que una vez que se haya logrado bajar la inflación a cerca de $30 \%$ sea deseable una nueva reducción tan brusca como la que ha planteado el gobierno ecuatoriano. Si bien existe consenso acerca de los costos que genera la inflación $\mathrm{y}$, por lo tanto, de los beneficios de que ella sea más baja -si es posible de un solo dígito anual - hay menos coincidencia respecto a la velocidad a la cual debe hacerse tal reducción. Esta suele depender de factores como la confianza en la política económica, el nivel de consenso en la sociedad alrededor de la meta de inflación propuesta, el avance de los cambios estructurales que tienen como fin mejorar la eficiencia de los mercados y, en general, la viabilidad política de acometer una estrategia de ajuste que suele llevar implícitos efectos recesivos y aumento del desempleo.

En el caso ecuatoriano, la política económica tiene credibilidad, ganada en virtud del éxito obtenido en 1993, cuando se logró reducir la inflación a niveles muy cercanos a la meta anunciada. Pero

\section{VI}

\section{Conclusiones}

El presente trabajo ha procurado ofrecer un análisis de la experiencia de estabilización que ha vivido el Ecuador a partir de septiembre de 1992, que ha permitido reducir la inflación desde un promedio de más de 50\% durante el período 1988-1992 a cerca de $30 \%$ al final de 1993.

Luego de revisar los antecedentes económicos del actual programa de estabilización, se han examinado las características más importantes de la estrate- también es cierto que en el Ecuador de hoy no existe consenso respecto a la estrategia de política económica que se ha planteado. El desacuerdo se da especialmente con los trabajadores, quienes se resisten a aceptar incrementos salariales de sólo $15 \%$ (meta de inflación para 1994), luego de un período prolongado en que el país vivió una inflación de más del 50\% en promedio, y de que en 1993 la inflación. fuera de $32 \%$.

Con los empresarios las diferencias se originan en el limitado avance de las reformas estructurales, y con ciertos grupos en particular, en la política de rezago cambiario. La viabilidad política se dificulta porque en 1994 habrá comicios electorales para renovar casi totalmente las dignidades parlamentarias, situación que limita la implantación de políticas de restricción de la demanda agregada. No es menos preocupante un posible entorno internacional desfavorable originado en la caída del precio mundial del petróleo, pues éste es el principal generador de ingresos fiscales y el primer rubro de exportación del país.

Por estas consideraciones, parecería que la estrategia de desinflación para 1994 debería ser más gradual, manteniendo firme la voluntad de perseverar en esa dirección en los años siguientes, hasta llegar a niveles similares a los de la inflación internacional. Esta alternativa no sólo sería menos costosa para la sociedad ecuatoriana, sino que además le permitiría al gobierno reactivar efectivamente el crecimiento en este año, y conservar la credibilidad de su política económica. De esta manera se haría sostenible la estrategia de desaceleración de la inflación y de reactivación de la economía ecuatoriana en una perspectiva de mediano y largo plazo. gia utilizada y los logros alcanzados hasta finales de 1993. Se ha destacado ante todo la disciplina fiscal ejercida, sin la cual no hubiera sido posible el éxito alcanzado. Complementariamente, se ha puesto de relieve la utilización del tipo de cambio como "ancla" nominal en el proceso de desinflación de la economía. Esta estrategia permitió romper en parte las expectativas inflacionarias preexistentes, a costa de relegar a un segundo plano el papel de la tasa de cam- 
bio como potencial instrumento de promoción del sector transable de la economía. Se define así un claro contraste con otros programas de ajuste adoptados en años anteriores en el Ecuador, en los cuales la política cambiaria estuvo orientada fundamentalmente al segundo de estos objetivos.

La experiencia reciente de estabilización en el Ecuador exhibe los beneficios de una política conjunta de austeridad fiscal y de anclaje en el tipo de cambio con el fin de desacelerar rápidamente el crecimiento de los precios, para países que han vivido una inflación crónica. Visto de otra manera, se confirma lo observado en otros países de América Latina: la corrección del déficit fiscal es condición necesaria pero no suficiente para alcanzar una rápida baja de la inflación.

El resultado alcanzado muestra, además, que no obstante el establecimiento del "ancla" cambiaria, la reducción de las tasas de interés reales y la inexistencia de un elevado nivel de indización, la baja de la inflación ha ido acompañada de un menor crecimiento económico, sobre todo de los sectores transables (excluido el petróleo). También se observa un resultado atípico en la balanza comercial, ya que su deterioro es modesto no obstante la apreciación real del tipo de cambio; esta situación se explica por la drástica caída de las importaciones, excepción hecha de las de bienes de consumo que tuvieron un significativo crecimiento. La baja de las importaciones de materias primas y bienes de capital es coherente con la desaceleración de la actividad económica, mientras que el crecimiento de las importaciones de bienes de consumo responde a la apreciación real del tipo de cambio.

El estudio realizado también destaca la lentitud con la que avanzan los cambios estructurales anunciados por el gobierno y la inexistencia de programas sociales dirigidos a atenuar el costo del ajuste. Lo primero tiende a limitar la eficiencia que se espera de los mercados, y genera alguna incertidumbre respecto a la viabilidad de la estabilización a mediano y largo plazo. Lo segundo no ha favorecido un clima de concertación social que permita que el camino de la estabilización sea menos tortuoso.

Por último, al reflexionar acerca de la conveniencia de definir hacia adelante una estrategia dirigida a bajar rápidamente la inflación del 32 al $15 \%$ en 1994, tal como lo ha anunciado el gobierno, se concluye que, una vez que se han alcanzado niveles de inflación más manejables, quizás sea más aconsejable una reducción gradual, que permita al mismo tiempo reactivar el crecimiento de la economía, manteniendo como objetivo de mediano plazo lograr una reducción de la inflación a un nivel similar al de la economía mundial.

\section{Bibliografía}

Adams, C. y D. Gros (1986): The consequences of real exchange rate rules for inflation: Some illustrative examples, Staff Papers, vol. 33, $\mathrm{N}^{\circ}$ 3, Washington, D.C., Fondo Monetario Internacional (FMI), septiembre.

Banco Central del Ecuador (1992), Plan Macroeconómico de Estabilización, Quito.

(1993): Cuentas trimestrales, $\mathrm{N}^{\circ} 8$, Quito.

- (varios números): Información estadística mensual, Quito.

Calvo, G., L. Leiderman y C. Reinhart (1993): Capital inflows and real exchange rate appreciation in Latin America, Staff $\mathrm{Pa}$ pers, vol. $40, \mathrm{~N}^{\circ} 1$, Washington, D.C., FMI, marzo.

Corden, W. M. (1984): Booming sector and Dutch disease economics: survey and consolidation, Oxford Economic Papers, vol. 36, No 3, Oxford, Reino Unido, Oxford University Press, noviembre.

Corden M. y P. Neary (1982): Booming sector and deindustrialization in a small open economy, The Economic Joumal, vol. 92, Cambridge, Reino Unido, Royal Economic Society, diciembre.

De la Torre, A. (1987): Macroeconomic Aspects of a Petroleum Boom: Ecuador 1972-1980, tesis de doctorado, Universidad de Notre Dame.

Dornbusch, R. y S. Fisher (1993): Moderate inflation, The World Bank Economic Review, vol. 7, No 1, Washington, D.C., Banco Mundial, enero.
Fernández, R. (1992): Transición de inflaciones intermedias a tasas de un dígito. El caso argentino. Ponencia presentada en la LV Reunión de Gobernadores de Bancos Centrales de América Latina y de España, Curazao, Centro de Estudios Monetarios Latinoamericanos (CEMLA), septiembre, mimeo.

FMI (Fondo Monetario Internacional) (varios números): Estadísticas financieras internacionales, Washington, D.C.

Jácome, L.I. (1989): Enfermedad Holandesa: impacto macroeconómico y crecimiento de la economía ecuatoriana entre 1972 y 1980, Quito, Corporación de Estudios para el Desarrollo (CORDES), mimeo.

Jadresic, E. (1992): De inflación moderada a inflación baja. Ponencia presentada en la XXIX Reunión de Técnicos de Bancos Centrales del Continente Americano, Barbados, CEMLA, noviembre.

Kiguel, M. y N. Liviatan (1992): The business cycle associated with the exchange rate-based stabilizations, The World Bank Economic Review, vol. 6, № 2, Washington, D.C., Banco Mundial, mayo.

Krugman, P. (1979): A model of balance of payments crisis, Journal of Money, Credit and Banking, vol. 11, Columbus, Ohio State University Press, agosto.

Mancera, M. (1992): Transición de inflaciones moderadas a niveles de un dígito. Ponencia presentada en la LV Reunión de 
Gobernadores de Bancos Centrales de América Latina y de España, Curazao, CEMLA, septiembre.

Montiel, P. y J. Ostry (1991): Macroeconomic implications of real exchange rate targeting in developing countries, Staff Papers, vol. 38, $\mathrm{N}^{\circ} 4$, Washington, D.C., diciembre.

Solimano, A. (1990): Inflation and the costs of stabilization: histo- rical and recent experiences and policy lessons, The World Bank Research Observer, vol. 5, $\mathrm{N}^{\circ} 2$, Washington, D.C., Banco Mundial, julio.

Végh, C. (1992): Stopping high inflation, Staff Papers, vol. 39, $\mathrm{N}^{\circ}$ 3, Washington, D.C., FMI, septiembre. 